\title{
Healthy Monitoring and Fault Detection Outer Race Bearing in Induction Motor Using Stator Current
}

\author{
Iradiratu Diah P K ${ }^{1 *}$, Belly Yan Dewantara ${ }^{1}$, Muhammad Abduh ${ }^{1}$, Sudirman ${ }^{1}$, \\ Wahyu Mulyo Utomo²,
}

${ }^{1}$ Department of Electrical Engineering, Faculty of Engineering and Marine Science, Hang Tuah University, Surabaya, 60111, Indonesia

${ }^{2}$ Department of Electrical Power Engineering, Universiti Tun Hussein Onn Malaysia, Johor, 86400, Malaysia

*Corresponding Author

DOI: https://doi.org/10.30880/ijie.2019.11.03.019

Received 24 July 2019; Accepted 31 July 2019; Available online 3 September 2019

\begin{abstract}
This paper describes a new method for monitor and detection bearing damage on induction motor. This is considered important because induction motors have an important role in the industry which functions as the main engine in the production process. This paper focuses on bearing damage because this is the most common case. the case of damaged bearing is done by giving the outer race bearing hole in three cases, $1 \mathrm{~mm}$ hole, $2 \mathrm{~mm}$ hole and 3 $\mathrm{mm}$ hole. Bearing damage analysis is carried out through a stator current signal on an induction motor, then the Fast Fourier transform (FFT) algorithm is used to see the characteristics of the frequency spectrum that appears in the stator current signal. High frequency analysis is applied to get clear analysis results. The results obtained by analyzing the frequency spectrum in the stator current that bearing damage indicate there is an amplitude that appears in the sideband frequency.
\end{abstract}

Keywords: Motor Current Signature Analysis, Bearing damage, Fast Fourier Transform, Induction motor, Outer race bearing.

\section{Introduction}

Nowadays, almost 70-80\% of industrial applications have used induction motors as the main driving component of the production process. induction motor damage causes important problems for users, especially if used in industries that can cause production process to stop [1-2]. Based on surveys conducted by Electric Power Research Institute (EPRI) on 6312 motors and IEEE-IAS Motor Reability Working Group on 1.141 motors almost 41-44\% induction motor damage occurs in the bearing [3-5]. Bearing damage based on location can be categorized as outer race bearing damage and inner race bearing damage. Bearing damage causes vibration, noise, increase in operating temperature, can even cause sparks due to friction between motor components that cause damage to other parts of the induction motor. [5]. Studies of bearing damage have been carried out by several previous researchers such as detecting bearing damage based on vibration analysis in [6], although this method is quite effective, analysis will get different results based on the location of sensor so it is difficult to determine the position of sensor. Paper [7], also conducted a bearing damage detection study using noise but in practice it did not show accurate results because there were other disturbing noise around. Paper [8] analyze magnetic flux from induction motors that contain a lot of harmonics. Observation through magnetic flux can produce very accurate results in monitoring motor conditions, this can be seen in the harmonic spectrum, but this method is not practical because it requires the installation of coils at the stator core, so that the motor operation must be stopped, and the small air gap also makes this method difficult to implement. Monitoring using a stator current analysis has also been carried out on [8-10], analysis on the stator current successfully performed detection analysis on rotor bar damage, airgap, 
stator winding, etc. The novelty in this paper is the use of high-resolution frequencies in analyzing stator currents to obtain more detailed analysis results so that amplitude observations can be carried out clearly and minimize errors.

\section{Bearing Damage Types}

Bearing construction consists of 4 important parts, outer race bearing, inner race bearing, balls and cages. Each part has its own function to make the rotor spin freely [2]. Bearing construction can be seen in Fig 1.

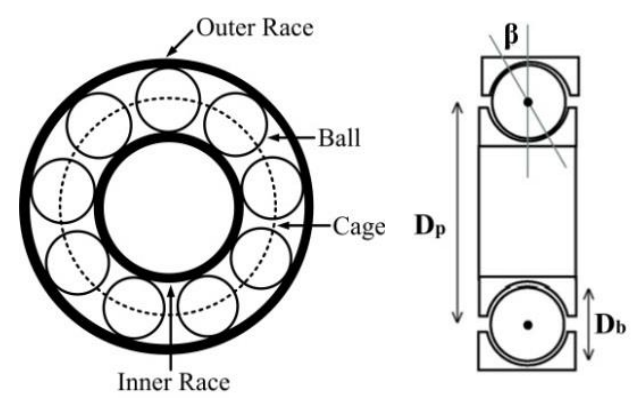

Fig. 1 - Construction of Bearings in Induction Motors

Bearing damage begins with small cracks because the induction motor works under normal conditions, varying loading conditions and misalignment of the rotor position. This can certainly be the cause of damage to other parts of the induction motor. In addition to mechanical factors, damage to the bearing can also be caused by external factors such as contamination, corrosion, lubrication errors, installation errors, and brinelling [9].

Contamination and corrosion are external factors that can cause damage to the bearing. This is influenced by bad environmental conditions and improper placement of induction motors. Dirt and dust are particles that can cause contamination of the bearing. While corrosion is caused by the chemical process between induction motors with other substances around it such as water, acids, and other substances [10].

Lubrication failure such as less or more lubrication on the bearing element is not recommended because it can cause overheating which can accelerate the process of bearing damage [10]. Installation errors occur due to improper bearing installation on the bearing house. This causes physical damage to the induction motor such as friction between the stator and rotor [12]. The missalignment of the rotor position due to installation errors causes eccentricity, disruption of the bearing that has an impact on the inner race and outer race bearing [11].

Bearing damage in each part has a different frequency of damage. In this paper only outer race damage is selected for analysis. When the three phase induction motor operates, the ball also rotates following the movement and direction of rotation of the rotor. The outer race bearing damage causes the bearing ball to experience direct contact with the damaged part so that the friction effect occurs. This is what causes the bearing to experience vibration, noise, and an increase in working temperature [13]. In general, bearings are located in two different places. At one place, the bearing is located on the main-shaft while on the other side the bearing is located on the fan-shaft [14]. In this paper the bearing varied is located on the fan-shaft. This can be done by opening the construction of the 3 phase induction motor used.

\section{Characteristic Frequencies of Stator Current}

Bearing damage in an induction motor causes the flux density in the air-gap to be asymmetrical and affect to the stator inductance. In this condition the stator current contains harmonics that can be predicted by the equation (1) [8][12].

$$
f_{\text {bng }}=\left|f_{e} \pm m f_{v}\right|
$$

Where, $f_{b n g}$ is prediction frequency of bearing demage, $f_{e}$ is electrical supply frequency, $m=1,2,3, \ldots$, and $f_{v}$ is one of the characteristic frequencies. Damage that occurs in induction motor bearings has a different frequency of bearing demage depending on the type of bearing damage. The frequency for each type of bearing damage can be seen in the equation (25) $[15]$.

$$
f_{o}=\frac{N_{B}}{2} f_{r m}\left(1-\frac{D_{B} \cos \theta}{D_{P}}\right)
$$




$$
\begin{array}{r}
f_{i}=\frac{N_{B}}{2} f_{r m}\left(1+\frac{D_{B} \cos \theta}{D_{P}}\right) \\
f_{b}=\frac{D_{B}}{2 D_{B}} f_{r m}\left(1-\frac{D_{B}^{2} \cos \theta}{D_{P}^{2}}\right) \\
f_{c}=\frac{1}{2} f_{r m}\left(1-\frac{D_{B} \cos \theta}{D_{P}}\right)
\end{array}
$$

Where, $f_{o}$ is outer race frequency, $f_{i}$ is inner race frequency, $f_{b}$ is bearing ball frequency, $f_{c}$ is bearing cage frequency, $N_{B}$ is number of ball, $f_{r m}$ is the mechanical rotor speed in hertz, $D_{B}$ is the ball diameter, $D_{P}$ is the ball pitch diameter, $\theta$ is the ball contact angel (typically equals to $0^{\circ}$ ).

Equations (2) to (5) are equations used to determine the value of the the exact characteristics frequency of the bearing based on the construction. In this case, with the ball bearings of 6 to 12 elements, the frequency of damage characteristics for the outer race and inner race can be determined using equation (6) and equation (7) [16].

$$
\begin{gathered}
f_{o}=0.4 N_{B} f_{r m} \\
f_{i}=0.6 N_{B} f_{r m}
\end{gathered}
$$

Where, $f_{o}$ is outer race bearing frequency characteristics, $f_{i}$ outer race bearing frequency characteristics,

\section{Fast Fourier Transform (FFT)}

Fast Fourier Transform (FFT) is a fast calculation method of Discrete Fourier Transform (DFT). DFT is a calculation method that converts signals from the time domain to the frequency domain [17]. Usually DFT is used for the purposes of spectrum analysis in the frequency domain [18]. By using DFT, a signal can be seen as an object in the frequency domain. DFT is more suitable for periodic discrete signals and symmetry. Periodic and symmetric discrete signals are discrete signals that repeat over a period of time and have a mirror around their midpoint. Mathematically, DFT of a discrete signal $\mathrm{x}$ [n] using $\mathrm{N}$ points can be seen in equations (8) and (9) [19].

$$
\begin{aligned}
& X(k)=\sum_{n=0}^{N-1} x[n] W_{N}^{n k}, k=1,2,3 \ldots N-1 \\
& W_{N}=e^{-j \frac{2 \pi}{N}}
\end{aligned}
$$

In numerical calculations the DFT computational load is quite heavy because it requires a number of complex $N^{2}$ multiplications. Whereas FFT has a lighter computing load by only requiring a number of (N/2)log_base2 (N) complex multiplications. FFT with the computational load is for radix-2 type FFT [19-20].

The stator current analysis using Fast Fourier Transform method is used to view the stator current from the time domain to frequency domain. This analysis method has been widely used to diagnose motor interferences. The success of frequency-based analysis is depended on the frequency resolution level. The frequency resolution corresponds to the total length of time range to consider sample numbers and sampling frequencies are used. The more the sample numbers are used, the more detail signal representation will be. While the greater sampling frequency are used, the longer FFT frequency range will be. Mathematically the resolution frequency can be seen in (8) [20].

$$
\Delta f=\frac{f s}{N}=\frac{1}{N . T s}
$$

Where $\Delta f$ is the frequency of resolution, $f_{s}$ is the sampling frequency, $T_{s}$ is the sampling period, and $N$ is the length of data used. 


\section{Experimental Setup}

This experiment consists of main equipment such as 3 phase induction motor 2 HP, 220/380 volt, 4 poles, speed $1390 \mathrm{rpm}$ and equipped with 2 bearing balls. Other experimental support such as AC power sources, mechanical loading is a generator that is combined with a bulb lamp, and data acquisition equipment connected to a computer and supporting software for processing data are Labview, Diadem, and Matlab.

\subsection{Bearing Damage Detection Techniques}

Monitoring an induction motor condition by analyzing the frequency spectrum of stator current is a new measurement technique that uses computational processing and data acquisition. The FFT algorithm is used to change data acquisition which is the current signal in time domain to be a current signal in frequency domain. Several previous techniques, the vibration analysis used to monitor and detect motor damage but stator current analysis is more widely used because it provides the same application without requiring direct physical contact on the motor, this method is known by the name Motor Current Signature Analysis (MCSA). Fig. 2 shows the scheme of monitoring induction motor conditions carried out in three processing parts: data acquisition, FFT transformation analysis, bearing damage monitoring and detection.

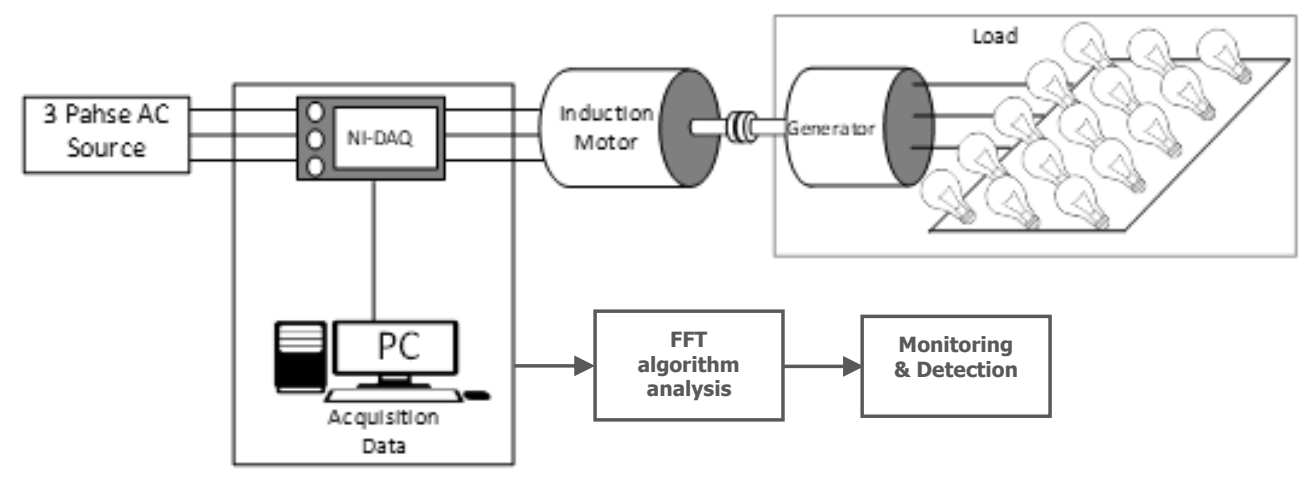

Fig. 2 - Bearing damage monitoring scheme in single phase stator current

The stator current sampling process is carried out for damage analysis purposes. Sampling data from stator current was carried out using a sampling frequency of 50,000 Hz/s with a total data length of $250 \mathrm{kHz}$. This value is deliberately chosen so that the band frequency is longer and detailed when data from the time domain is transformed into the frequency domain for analysis purposes. The sampling results are stator current signals in the time domain, then transformed in the frequency domain using a fast fourier transformation algorithm, signals in the frequency domain show some amplitude that appears around fundamental frequency. Equation (2) is used to predict the amplitude that occurs due to outer race bearing damage, then the amplitude of the outer race bearing damage is compared to the amplitude of healty bearing in the same frequency predictable. Diagnosis of damaged and healthy bearing conditions can be concluded based on changes in the magnitude of the amplitude that appears at the location of the predicted frequency damage.

\subsection{Reconstruction of Outer Race Bearing Damage}

Bearing damage reconstruction is made by providing defects in outer race bearing. Damage reconstruction is made by making a hole $2 \mathrm{~mm}$ in diameter with a variety of cases 1 hole, 2 holes and 3 holes each bearing that shows fig. 3 . This variation of damage holes is intended so that the data produced can be measured based on the severity, even though in reality bearing damage occurs with an undetermined severity. The results of the reconstruction can be seen in Fig 3 , while bearing specifications can be seen in table 1 .

Table 1 - Spesification of bearing

\begin{tabular}{cccc}
\hline \hline Merk & ASB & Ball Bearing & 9 \\
\hline Type & $6205 \mathrm{ZZ}$ & Wide Bearing & $15 \mathrm{~mm}$ \\
\hline Inner Race & $25 \mathrm{~mm}$ & Outer Race & $52 \mathrm{~mm}$ \\
\hline \hline
\end{tabular}




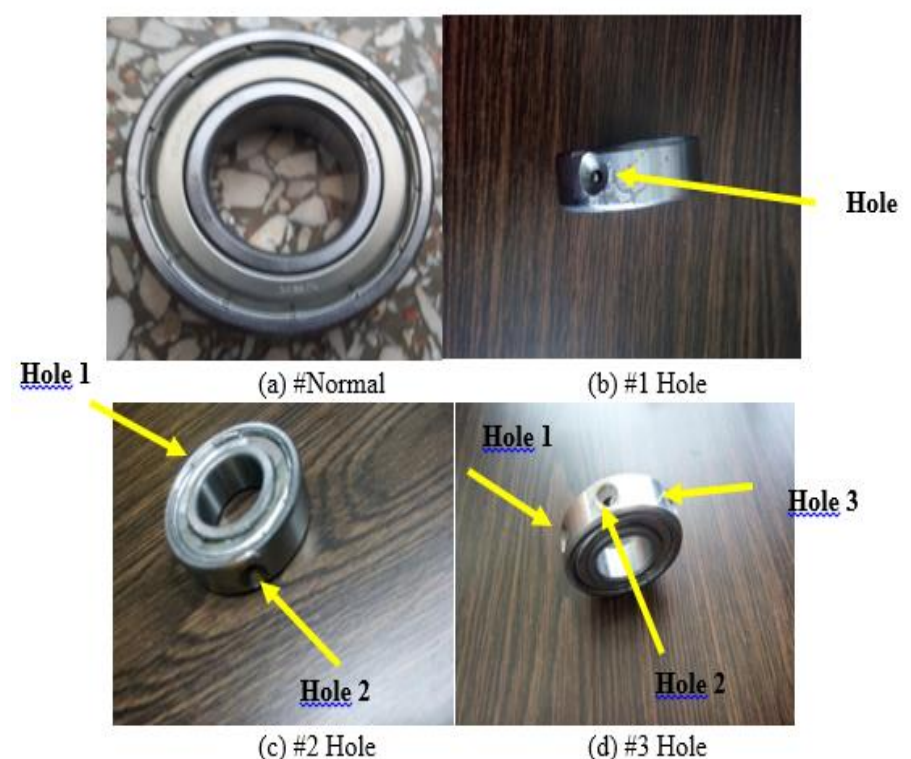

Fig. 3 - Reconstruction of outer race bearing damage

\section{Analysis of Stator Current Spectrum on Different Damage Cases}

This section describes the results of experiments that have been carried out on the analysis of error detection on the outer race bearing through the spectrum frequency in the stator current. Testing is done by comparing the results of the frequency spectrum analysis on a normal motor with motor bearing damage. In this experiment observations were carried out at 20 points of damage frequency using a constant value $\mathrm{m}=1 \ldots 10$, this is needed to facilitate observation and improve accuracy in the analysis of damage amplitude. The frequency point is determined based on equation (2), with the case of outer race bearing damage being made varying into 3 cases, first case ( 1 hole's bearing), second case ( 2 hole's bearing), and third case ( 3 hole's bearing).

\subsection{Determine The Threshold Amplitude}

Threshold amplitude need to be determined as the first step for the detection process. The threshold amplitude will be used as a reference in order to identify healthy bearings and damaged bearings. Stator current data on motors with healthy bearings is sampled in no load, half load and full load conditions. The current signal obtained is transformed in the frequency domain using FFT. Bearing damage prediction based on equation (2) is used to sample the amplitude to be used as a comparison with the frequency spectrum of bearing damage. Fig. 4 - Fig. 6 are healthy bearing frequency spectrum in three load variations. Each load has a different amplitude, so it will be used to calculate the average amplitude of each prediction frequency based on all load variations.

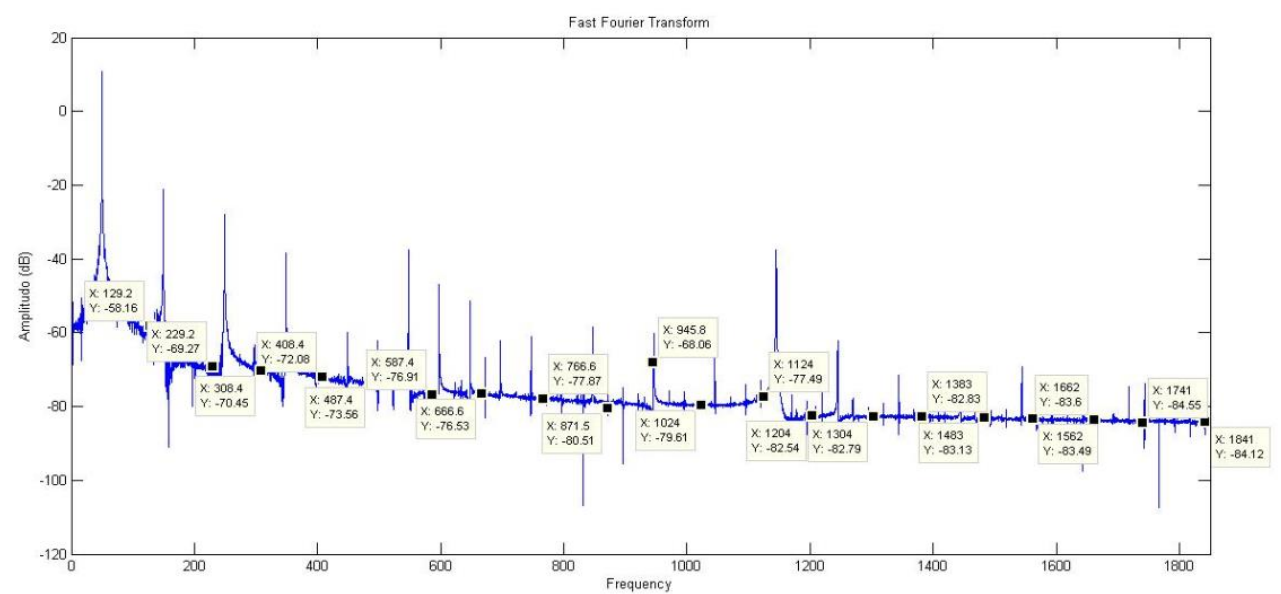

Fig. 4 - The frequency spectrum of healthy bearing - no load 


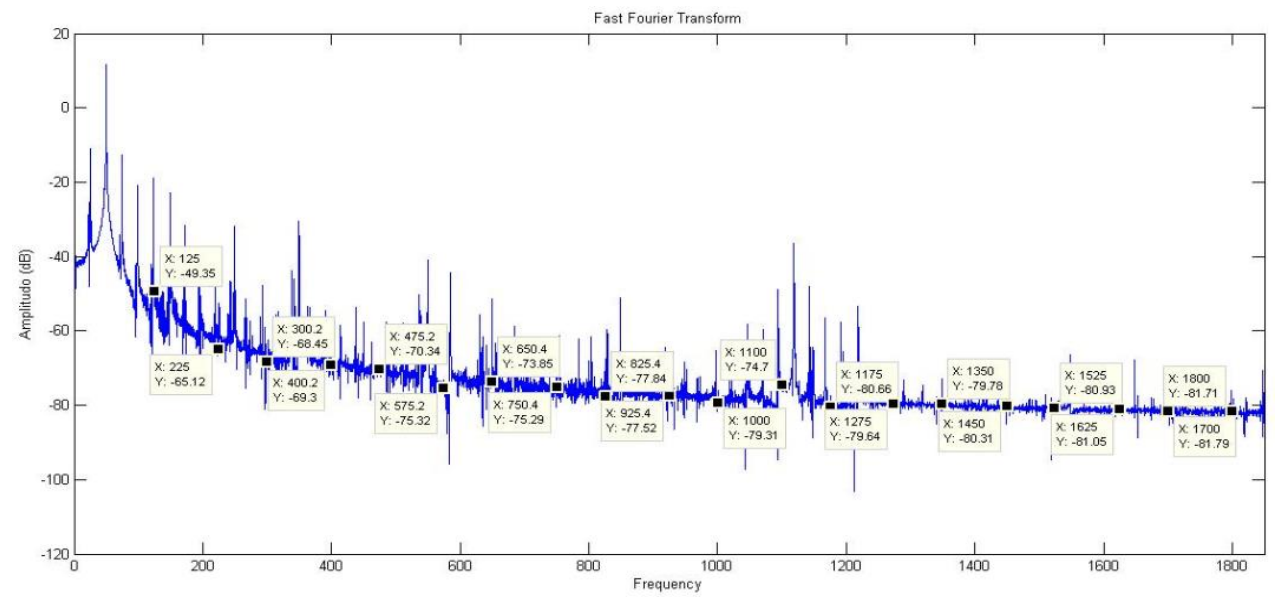

Fig. 5 - The frequency spectrum of healthy bearing - half load

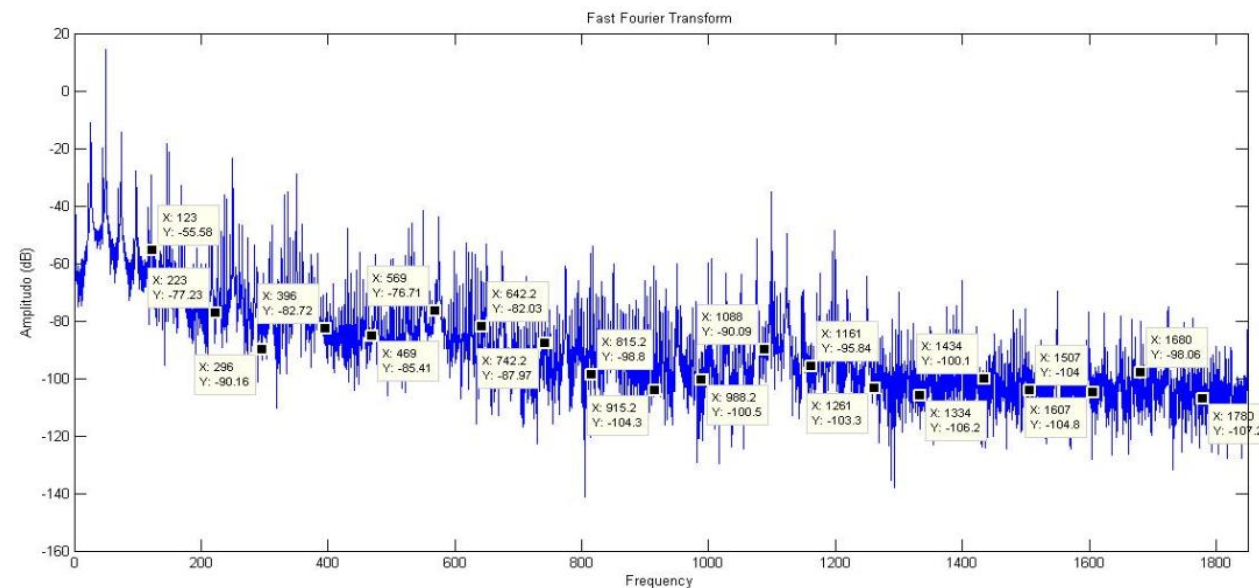

Fig. 6 - The frequency spectrum of healthy bearing - full load

Fig. 4-6 shows different frequency spectrums of three variations in load conditions. The results of the plotting amplitude at each prediction frequency are shown in table 2 .

Table 2 - The amplitude value of the determined threshold

\begin{tabular}{ccccc}
\hline Constant & \multicolumn{4}{c}{ Amplitude $(\mathrm{dB})$} \\
\cline { 2 - 5 }$(k=1,2,3, . .10)$ & No load & Half load & Full load & Avg (Threshold) \\
\hline$f_{\mathrm{p}}(\mathrm{k}=1)$ & -57.09 & -64.11 & -64.83 & -62.11 \\
$f_{\mathrm{p}}(\mathrm{k}=-1)$ & -54.26 & -48.34 & -55.58 & -52.87 \\
$f_{\mathrm{p}}(\mathrm{k}=2)$ & -65.52 & -69.3 & -65.23 & -67.84 \\
$f_{\mathrm{p}}(\mathrm{k}=-2)$ & -64.39 & -68.45 & -64.26 & -65.76 \\
$f_{\mathrm{p}}(\mathrm{k}=3)$ & -69.14 & -72.12 & -68.78 & -71.03 \\
$f_{\mathrm{p}}(\mathrm{k}=-3)$ & -66.18 & -70.12 & -70.15 & -69.90 \\
$f_{\mathrm{p}}(\mathrm{k}=4)$ & -71.92 & -75.29 & -71.72 & -74.16 \\
$f_{\mathrm{p}}(\mathrm{k}=-4)$ & -69.89 & -68.37 & -71.83 & -71.52 \\
$f_{\mathrm{p}}(\mathrm{k}=5)$ & -69.82 & -76.96 & -72.41 & -74.92 \\
$f_{\mathrm{p}}(\mathrm{k}=-5)$ & -71.60 & -72.61 & -73.34 & -74.58 \\
$f_{\mathrm{p}}(\mathrm{k}=6)$ & -74.71 & -74.4 & -72.21 & -75.44 \\
$f_{\mathrm{p}}(\mathrm{k}=-6)$ & -73.23 & -78.99 & -73.77 & -76.18 \\
$f_{\mathrm{p}}(\mathrm{k}=7)$ & -74.05 & -78.26 & -76.11 & -77.96 \\
$f_{\mathrm{p}}(\mathrm{k}=-7)$ & -73.66 & -75.85 & -75.32 & -76.84 \\
$f_{\mathrm{p}}(\mathrm{k}=8)$ & -75.59 & -79.41 & -76.70 & -79.18 \\
$f_{\mathrm{p}}(\mathrm{k}=-8)$ & -74.8 & -79.78 & -76.35 & -78.75 \\
$f_{\mathrm{p}}(\mathrm{k}=9)$ & -76.23 & -79.98 & -77.48 & -80.38 \\
$f_{\mathrm{p}}(\mathrm{k}=-9)$ & -76.04 & -80.69 & -77.12 & -79.22 \\
$f_{\mathrm{p}}(\mathrm{k}=10)$ & -76.63 & -81.02 & -77.9 & -79.13 \\
$f_{\mathrm{p}}(\mathrm{k}=-10)$ & -76.91 & -80.49 & -77.19 & -79.22
\end{tabular}


Table 2 shows, in the gray area is the average amplitude obtained from the calculation at each location of the bearing damage frequency. The amplitude value is used as a threshold to determine the bearing health and bearing damage conditions. The bearing of motor is identified as healthy if the amplitude that appears at the prediction frequency location is lower than the threshold amplitude. Vice versa, a bearing motor damage is detected if the amplitude at the prediction frequency is higher than the threshold amplitude.

\subsection{Frequency Spectrum on Stator Current Analysis - No Load Condition (0\%)}

Testing of induction motors in no-load conditions with variations in bearing damage, 1 hole (case 1), 2 holes (case 2), and 3 holes (case 3). The results show that there are differences in the amplitude value between healthy bearing (blue) compared to bearing damage (red). The frequency spectrum in case 1 (fig 7) shows a graph sampled at a frequency of $500 \mathrm{~Hz}$ to $1500 \mathrm{~Hz}$, the amplitude at the prediction frequency $k=3(574.2 \mathrm{hz})$ has increased amplitude of $-58.59 \mathrm{~dB}$ greater than the threshold amplitude $-71.03 \mathrm{~dB}$. The amplitude value of the constant $k=-5, k=5, k=6, k=-8$ also has an increase in amplitude exceeding the threshold. Amplitude at 20 points of prediction frequencies in case 1, there were 13 amplitudes that exceeded the threshold or the system could detect damage bearing by $65 \%$ success. In case 2 (fig 8 ) with an indication of bearing experiencing 2 holes in the outer race bearing, indicating that there are 12 points which have increased beyond the threshold. In case 3 (fig 9) shows that there are 13 frequency points that have amplitude exceeding the threshold amplitude. The percentage of success of each case can be seen in table 2.

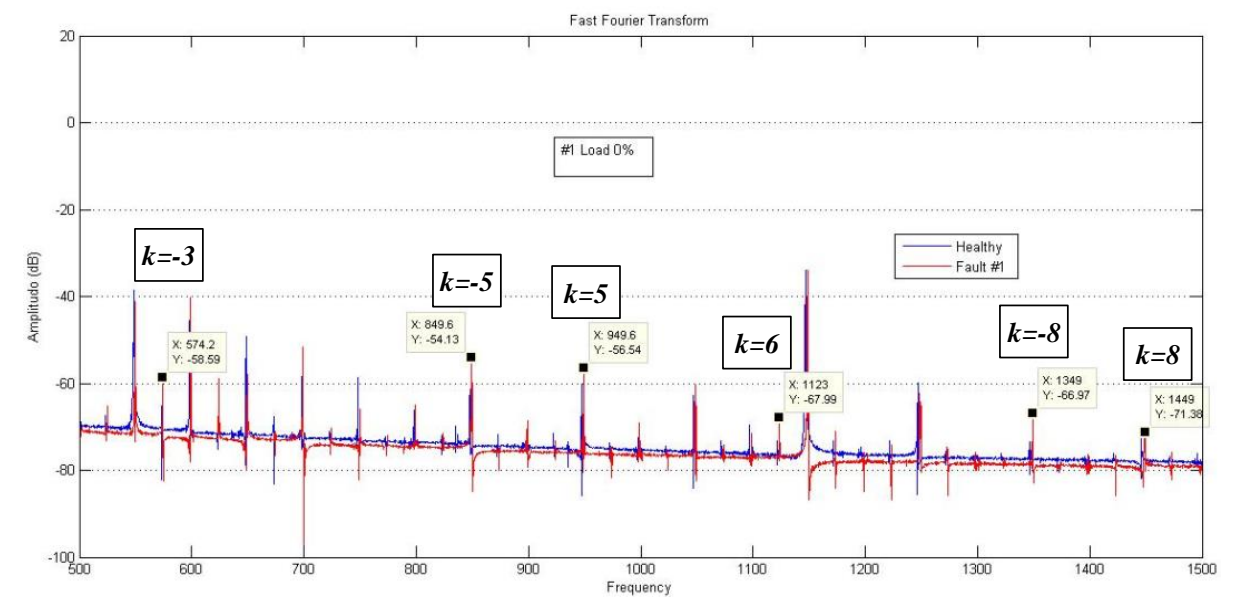

Fig. 7 - Frequencies spectrum of Case 1 - No load

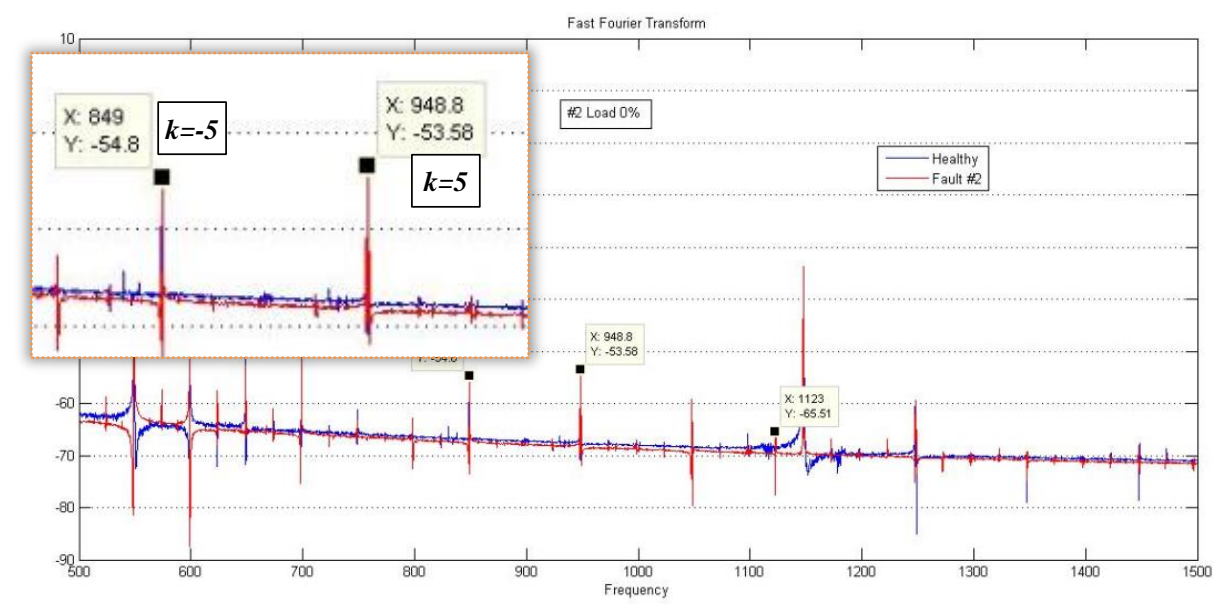

Fig. 8 - Frequencies spectrum of Case 2 - No load 


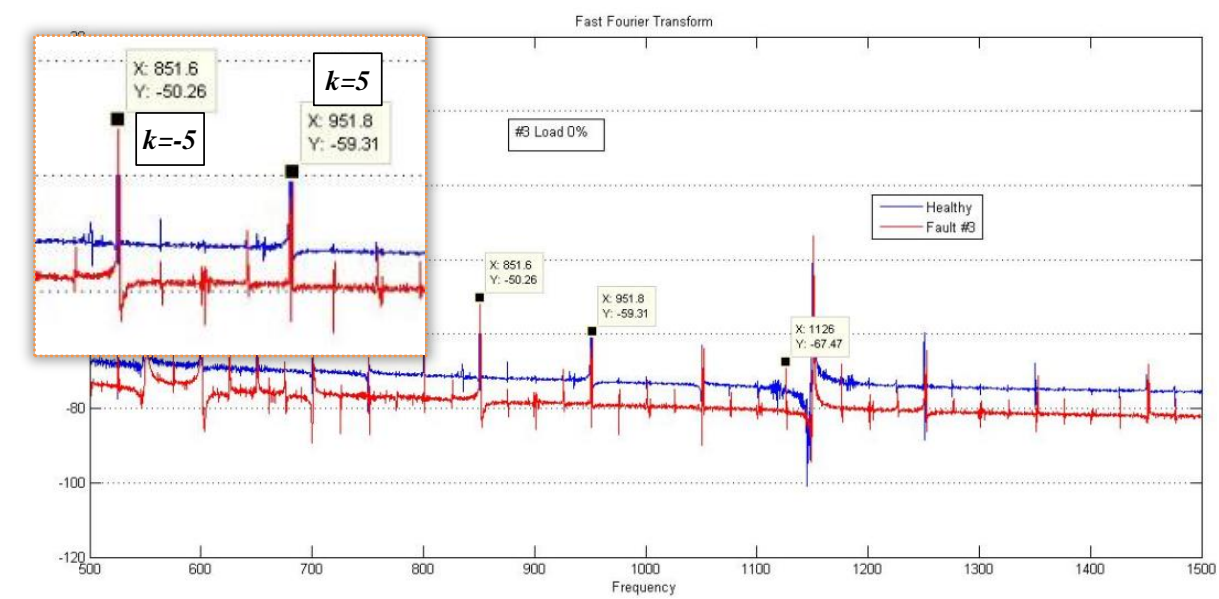

Fig. 9 - Frequencies spectrum of Case 3 - No load

Table 3 - Predictable frequencies and amplitude for all cases - no load (0\%)

\begin{tabular}{cccccccc}
\hline \multirow{2}{*}{ Constant } & Threshold & \multicolumn{2}{c}{ Case \#1 } & \multicolumn{2}{c}{ Case \#2 } & \multicolumn{2}{c}{ Case \#3 } \\
\cline { 3 - 8 } & Amp (dB) & Freq (Hz) & Amp (dB) & Freq (Hz) & Amp (dB) & Freq (Hz) & Amp (dB) \\
\hline$f_{p}(k=1)$ & -62.11 & 224.8 & -58.89 & 224.8 & -58.83 & 229 & -61.39 \\
$f_{p}(k=-1)$ & -52.87 & 128.8 & -57.81 & 127.8 & -59.91 & 129 & -49.78 \\
$f_{p}(k=2)$ & -67.84 & 407.8 & -69.24 & 407.6 & -71.34 & 408.2 & -61.39 \\
$f_{p}(k=-2)$ & -65.76 & 310.2 & -67.34 & 307.2 & -58.9 & 308.6 & -58.54 \\
$f_{p}(k=3)$ & -71.03 & 574.2 & -58.59 & 587.8 & -74.48 & 587.2 & -72.48 \\
$f_{p}(k=-3)$ & -69.90 & 474.8 & -65.98 & 487.8 & -68.62 & 486.4 & -63.28 \\
$f_{p}(k=4)$ & -74.16 & 770.2 & -73.64 & 767.4 & -72.69 & 767 & -76.82 \\
$f_{p}(k=-4)$ & -71.52 & 670 & -72.97 & 667.6 & -74.26 & 667.8 & -79.5 \\
$f_{p}(k=5)$ & -74.92 & 949.6 & -56.54 & 948.8 & -53.58 & 951.8 & -58.96 \\
$f_{p}(k=-5)$ & -74.58 & 849.6 & -54.13 & 849 & -54.80 & 851.6 & -50.26 \\
$f_{p}(k=6)$ & -75.44 & 1123 & -67.99 & 1123 & -65.51 & 1126 & -67.47 \\
$f_{p}(k=-6)$ & -76.18 & 1024 & -75.15 & 1023 & -79.42 & 1026 & -77.92 \\
$f_{p}(k=7)$ & -77.96 & 1309 & -78.6 & 1308 & -79.69 & 1305 & -83.09 \\
$f_{p}(k=-7)$ & -76.84 & 1209 & -77.9 & 1208 & -78.06 & 1205 & -82.99 \\
$f_{p}(k=8)$ & -79.18 & 1449 & -71.38 & 1488 & -77.41 & 1486 & -62.15 \\
$f_{p}(k=-8)$ & -78.75 & 1349 & -66.97 & 1388 & -76.06 & 1385 & -61.55 \\
$f_{p}(k=9)$ & -80.38 & 1668 & -80.05 & 1669 & -64.08 & 1664 & -82.36 \\
$f_{p}(k=-9)$ & -79.22 & 1568 & -79.3 & 1569 & -68.82 & 1564 & -72.33 \\
$f_{p}(k=10)$ & -79.13 & 1849 & -76.53 & 1848 & -67.49 & 1854 & -62.33 \\
$f_{p}(k=-10)$ & -79.22 & 1749 & -74.66 & 1747 & -79.31 & 1752 & -71.59 \\
\hline Percentage detection & & $65 \%$ & & & & $65 \%$ \\
\hline
\end{tabular}

\subsection{Frequency spectrum on stator current analysis - load condition (50\%)}

In this section, the analysis is carried out in the condition that the motor is given a half load. Table 4 shows the results of testing in three different cases. In case 1 ( 1 hole at bearing) the amplitude that appears at the prediction frequency has a value above amplitude threshold. The success percentage of detection in case 1 is $100 \%$. Analysis in case 2 ( 2 hole at bearing) also shows some amplitude that has a value above the threshold, but there is something unique in fig 6 , the frequency spectrum of healthy bearings is higher than the bearing damage spectrum. This occurs because of the impact on voltage changes when retrieving data so that it impacts on the value of the stator current sampled. Spectrum equalization of healthy bearings and damaged bearings is carried out to obtain the correct analysis results. In case 3 (3 hole at bearing) it is clear there is an increase in amplitude at the prediction frequency, the success percentage of detection in case 3 reaches $100 \%$. The frequency spectrum in cases 1-3 can be seen in figure 10-12. 
Table 4 - Predictable frequencies and amplitude for all cases - Half load (50\%)

\begin{tabular}{|c|c|c|c|c|c|c|c|}
\hline \multirow{2}{*}{ Constant } & \multirow{2}{*}{$\begin{array}{l}\text { Threshold } \\
\text { Amp (dB) }\end{array}$} & \multicolumn{2}{|c|}{ Case \#1 } & \multicolumn{2}{|c|}{ Case \#2 } & \multicolumn{2}{|c|}{ Case \#3 } \\
\hline & & Freq $(\mathrm{Hz})$ & $\operatorname{Amp}(d B)$ & Freq $(\mathrm{Hz})$ & $\operatorname{Amp}(\mathrm{dB})$ & Freq $(\mathrm{Hz})$ & $\operatorname{Amp}(\mathrm{dB})$ \\
\hline$f_{p}(k=1)$ & -62.11 & 225.4 & -46.60 & 225.8 & -50.26 & 224 & -57.31 \\
\hline$f_{p}(k=-1)$ & -52.87 & 125 & -44.33 & 123.4 & -18.45 & 123 & -24.53 \\
\hline$f_{p}(k=2)$ & -67.84 & 401.2 & -58.07 & 401.2 & -66.06 & 397.9 & -61.68 \\
\hline$f_{p}(k=-2)$ & -65.76 & 300 & -56.19 & 301.2 & -62.51 & 297.6 & -57.76 \\
\hline$f_{p}(k=3)$ & -71.03 & 573 & -61.18 & 577 & -68.48 & 573.8 & -62.42 \\
\hline$f_{p}(k=-3)$ & -69.90 & 473.8 & -57.83 & 477.4 & -69.91 & 473.2 & -63.96 \\
\hline$f_{p}(k=4)$ & -74.16 & 749.4 & -63.49 & 753 & -71.45 & 747.8 & -59.63 \\
\hline$f_{p}(k=-4)$ & -71.52 & 649 & -61.50 & 651 & -56.05 & 648.2 & -59.6 \\
\hline$f_{p}(k=5)$ & -74.92 & 925 & -63.07 & 929.4 & -73.58 & 932.6 & -69.06 \\
\hline$f_{p}(k=-5)$ & -74.58 & 825.6 & -64.77 & 829.4 & -75.81 & 830.4 & -62.16 \\
\hline$f_{p}(k=6)$ & -75.44 & 1100 & -67.34 & 1101 & -46.57 & 1095 & -50.07 \\
\hline$f_{p}(k=-6)$ & -76.18 & 1000 & -66.06 & 1003 & -62.75 & 995.6 & -68.13 \\
\hline$f_{p}(k=7)$ & -77.96 & 1272 & -67.62 & 1280 & -75.24 & 1272 & -72.98 \\
\hline$f_{p}(k=-7)$ & -76.84 & 1172 & -67.29 & 1180 & -76.39 & 1170 & -55.37 \\
\hline$f_{p}(k=8)$ & -79.18 & 1448 & -69.46 & 1456 & -76.11 & 1446 & -70.15 \\
\hline$f_{p}(k=-8)$ & -78.75 & 1349 & -67.86 & 1356 & -75.52 & 1346 & -66.35 \\
\hline$f_{p}(k=9)$ & -80.38 & 1622 & -69.40 & 1633 & -76.71 & 1621 & -74.07 \\
\hline$f_{p}(k=-9)$ & -79.22 & 1522 & -68.86 & 1533 & -76.82 & 1521 & -73.86 \\
\hline$f_{p}(k=10)$ & -79.13 & 1798 & -69.40 & 1806 & -77.02 & 1796 & -75.06 \\
\hline$f_{p}(k=-10)$ & -79.22 & 1697 & -69.68 & 1706 & -77.11 & 1696 & -74.5 \\
\hline \multicolumn{2}{|c|}{ Percentage detection } & \multicolumn{2}{|c|}{$100 \%$} & \multicolumn{2}{|c|}{$85 \%$} & \multicolumn{2}{|c|}{$100 \%$} \\
\hline
\end{tabular}

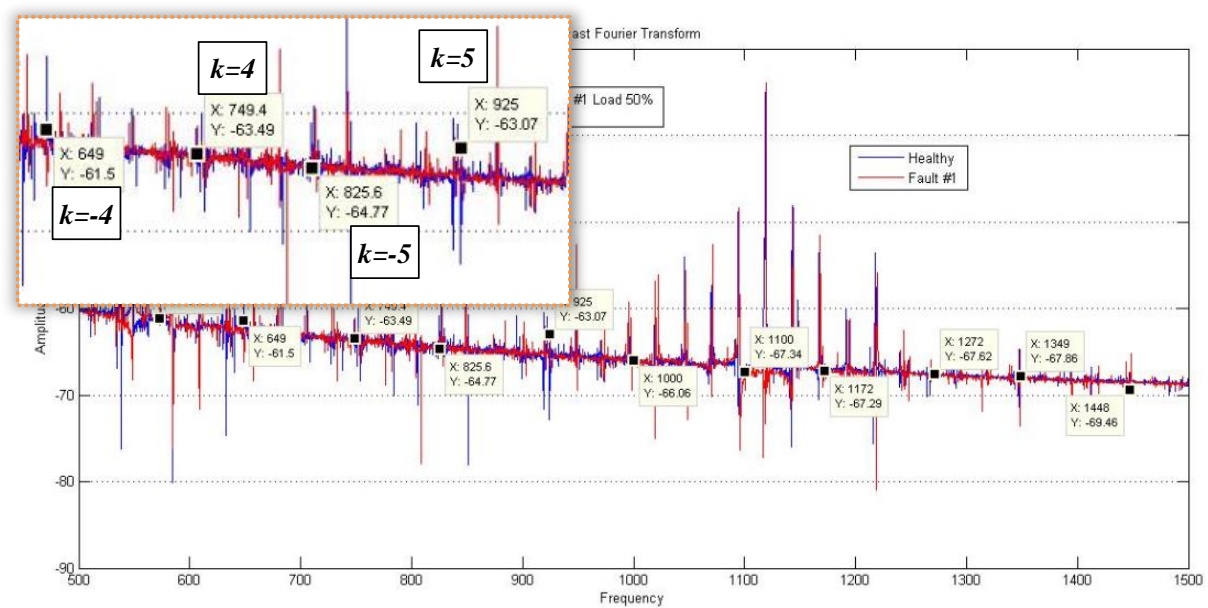

Fig. 10. Frequencies spectrum of Case 1 - half load

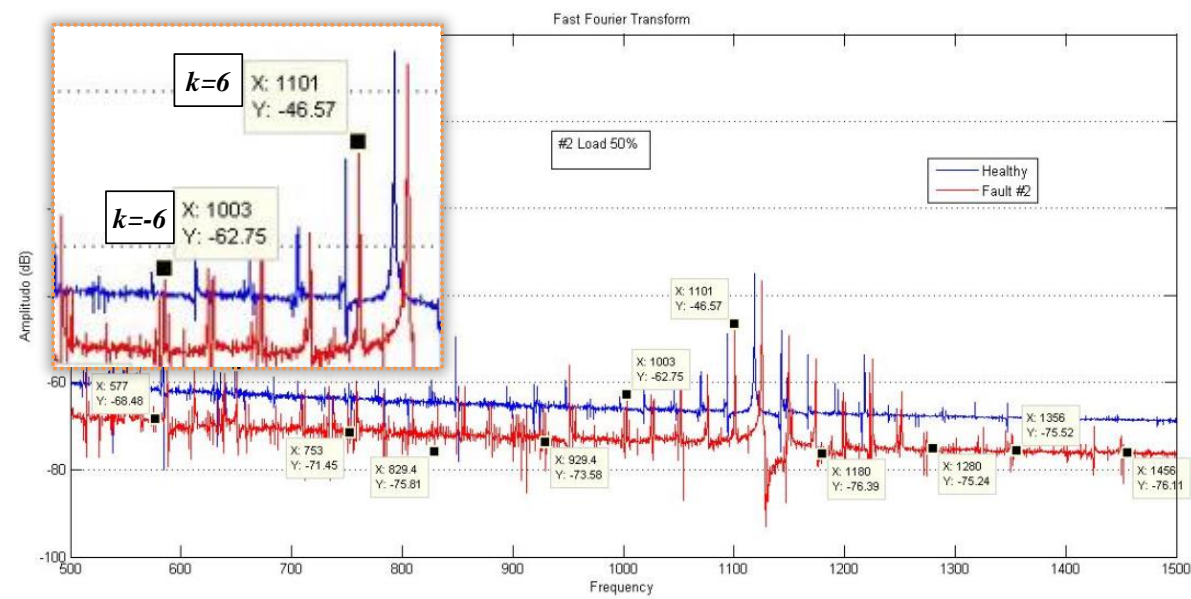

Fig. 11. Frequencies spectrum of Case 2 - half load 


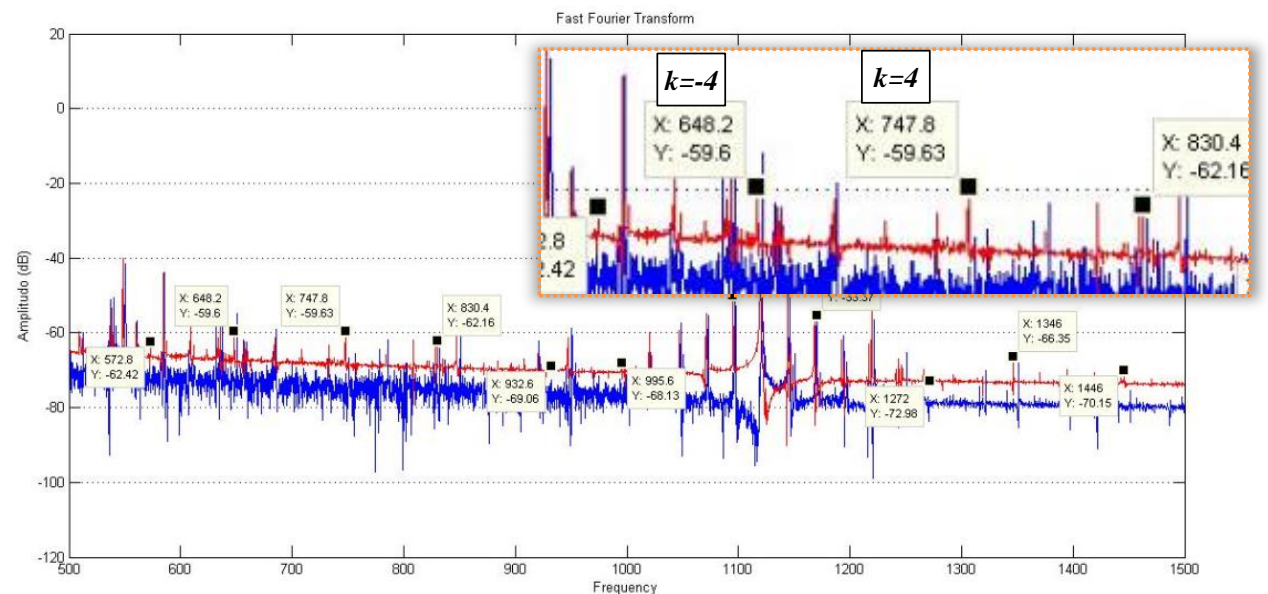

Fig. 12. Frequencies spectrum of Case 3 - half load

\subsection{Frequency spectrum on stator current analysis - full load condition (100\%)}

In this section, the analysis is carried out under full load conditions, Figure 13-15 shows appearance of amplitude at damage frequency spectrum. In case 1 there are 10 amplitudes that exceed the threshold, the success percentage of detection is $50 \%$. Case 2 shows the clear detection result, that damage amplitude appears higher than amplitude threshold, in this case the successful of percentage is $100 \%$. Case 3 shows that 13 envelopes have identified damaged bearings, the damage amplitude increases higher than the amplitude threshold, a success percentage of $65 \%$. The overall amplitude analysis results at the frequency location can be seen in the table 5 .

Table 4 - Predictable frequencies and amplitude for all cases - full load (100\%)

\begin{tabular}{|c|c|c|c|c|c|c|c|}
\hline & \multirow{2}{*}{$\begin{array}{l}\text { Threshold } \\
\text { Amp (dB) }\end{array}$} & \multicolumn{2}{|c|}{ Case \#1 } & \multicolumn{2}{|c|}{ Case \#2 } & \multicolumn{2}{|c|}{ Case \#3 } \\
\hline & & Freq $(\mathrm{Hz})$ & $\operatorname{Amp}(\mathrm{dB})$ & Freq $(\mathrm{Hz})$ & $\operatorname{Amp}(\mathrm{dB})$ & Freq $(\mathrm{Hz})$ & $\operatorname{Amp}(\mathrm{dB})$ \\
\hline$f_{p}(k=1)$ & -62.11 & 225.6 & -42.46 & 222.2 & -50.18 & 220.4 & -60.26 \\
\hline$f_{p}(k=-1)$ & -52.87 & 122 & -19.75 & 122.2 & -15.91 & 121.4 & -28.81 \\
\hline$f_{p}(k=2)$ & -67.84 & 397.4 & -62.97 & 398.6 & -56.17 & 397 & -67.48 \\
\hline$f_{p}(k=-2)$ & -65.76 & 297.6 & -56.1 & 298.4 & -49.58 & 297.2 & -54.26 \\
\hline$f_{p}(k=3)$ & -71.03 & 568.2 & -78.97 & 569.2 & -60.42 & 561 & -71.18 \\
\hline$f_{p}(k=-3)$ & -69.90 & 469.2 & -71.33 & 469.2 & -58.76 & 461 & -67.68 \\
\hline$f_{p}(k=4)$ & -74.16 & 741.5 & -90.07 & 741 & -62.54 & 739.2 & -73.9 \\
\hline$f_{p}(k=-4)$ & -71.52 & 641.8 & -82.75 & 641 & -61.53 & 639.2 & -72.39 \\
\hline$f_{p}(k=5)$ & -74.92 & 914.6 & -61.64 & 911.4 & -60.67 & 911.6 & -76.92 \\
\hline$f_{p}(k=-5)$ & -74.58 & 814.8 & -58.27 & 811.2 & -62.67 & 811 & -75.06 \\
\hline$f_{p}(k=6)$ & -75.44 & 1084 & -74.29 & 1084 & -49.69 & 1080 & -51.4 \\
\hline$f_{p}(k=-6)$ & -76.18 & 983 & -66.71 & 987.6 & -63.03 & 984.4 & -73.34 \\
\hline$f_{p}(k=7)$ & -77.96 & 1259 & -88.24 & 1256 & -67.08 & 1252 & -71.23 \\
\hline$f_{p}(k=-7)$ & -76.84 & 1159 & -76.25 & 1156 & -54.69 & 1152 & -56.58 \\
\hline$f_{p}(k=8)$ & -79.18 & 1435 & -82.16 & 1436 & -65.5 & 1427 & -76.37 \\
\hline$f_{p}(k=-8)$ & -78.75 & 1330 & -79.91 & 1336 & -67.37 & 1327 & -79.08 \\
\hline$f_{p}(k=9)$ & -80.38 & 1606 & -80.04 & 1604 & -67.99 & 1600 & -79.5 \\
\hline$f_{p}(k=-9)$ & -79.22 & 1506 & -80.86 & 1504 & -65.5 & 1500 & -79.27 \\
\hline$f_{p}(k=10)$ & -79.13 & 1778 & -97.27 & 1776 & -68.71 & -73.94 & -80.86 \\
\hline$f_{p}(k=-10)$ & -79.22 & 1676 & -91.27 & 1678 & -68.32 & 1679 & -73.94 \\
\hline \multicolumn{2}{|c|}{ Percentage detection } & \multicolumn{2}{|c|}{$50 \%$} & \multicolumn{2}{|c|}{$100 \%$} & \multicolumn{2}{|c|}{$65 \%$} \\
\hline
\end{tabular}




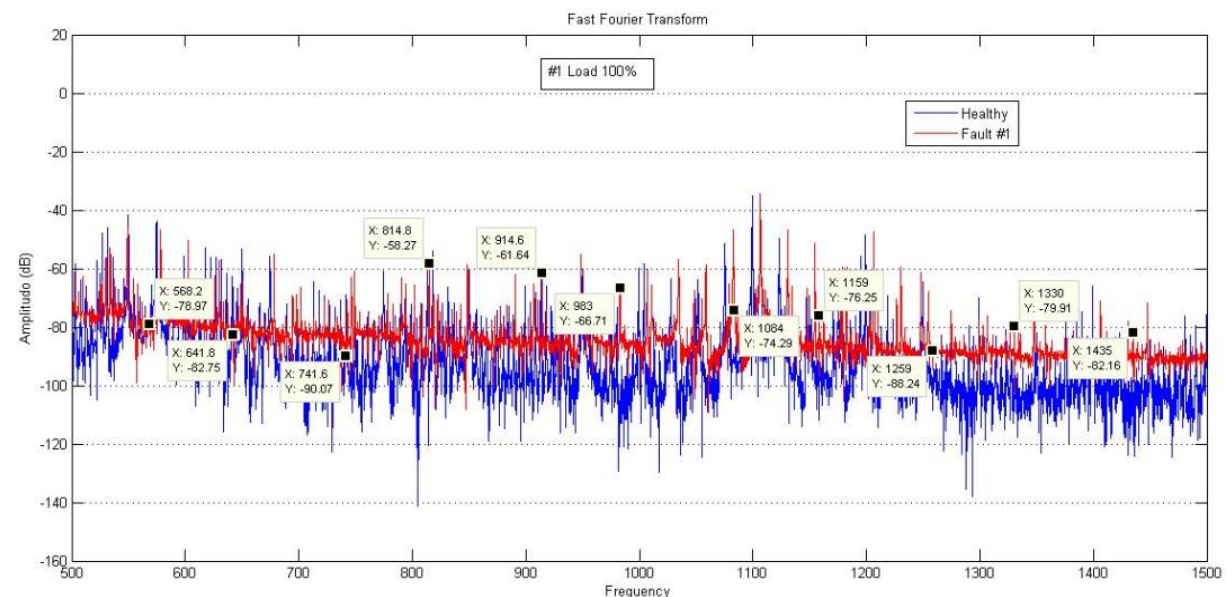

Fig. 13 - Frequencies spectrum of Case 1 - full load

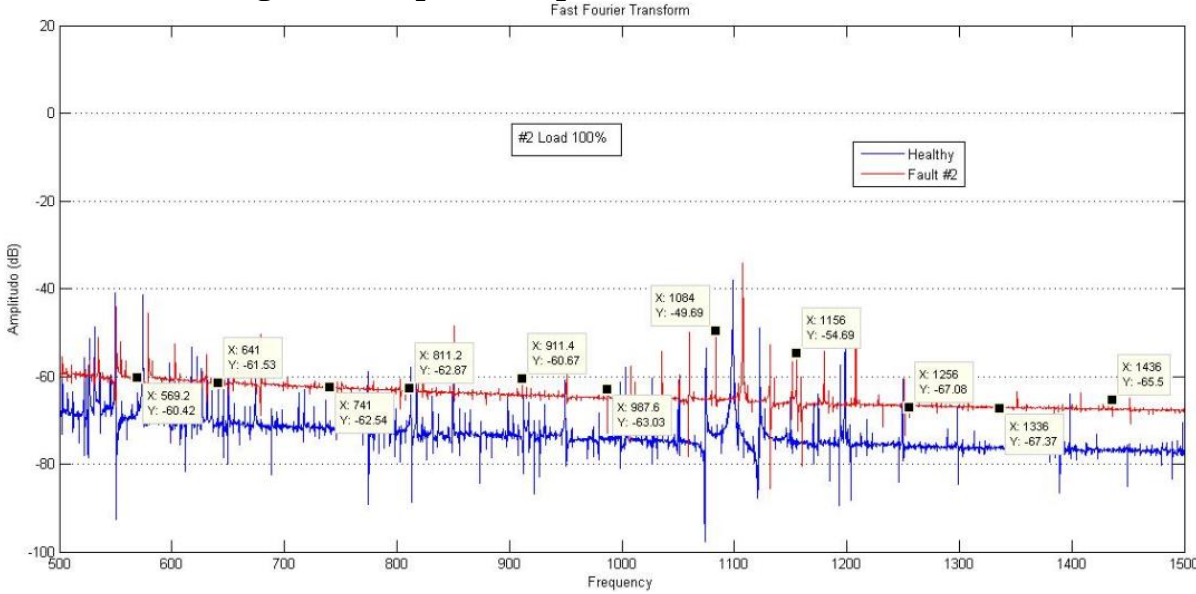

Fig. 14 - Frequencies spectrum of Case 2 - full load

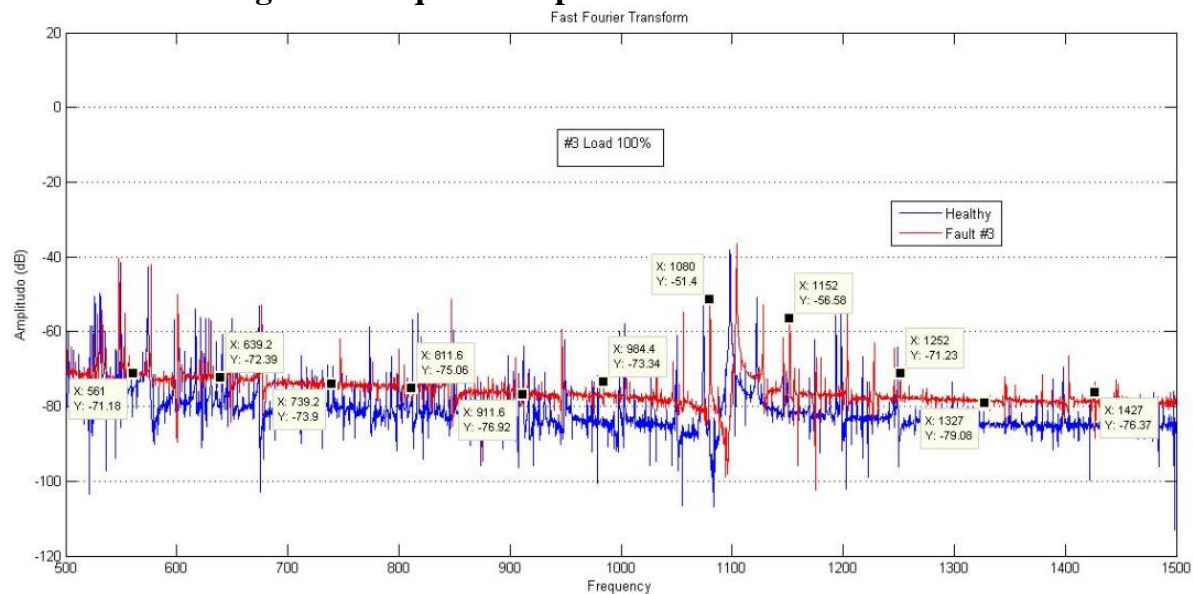

Fig. 15 - Frequencies spectrum of Case 3 - full load

The all experiments result show that the outer race bearing can be detected properly using a frequency spectrum analysis on stator current. Experiments analyzing bearing damage without load conditions to full load obtained very clear results even though variations of damage cases did not significantly affect the succes percentage of detection. This is indicated by the percentage of detections that are not linear to the more severe changes in damage. accuracy of percentage detection is more affected by load conditions change, indicated by differences in the no load and half load condition. While in full load conditions the difference in the percentage of each case is very far, different from no load and half load conditions. The possibility is that there is a damping produced by a mechanical load, a case like this also occurs on paper [15]. The percentage comparasion of each case in different load variations can be seen in Figure 16. 


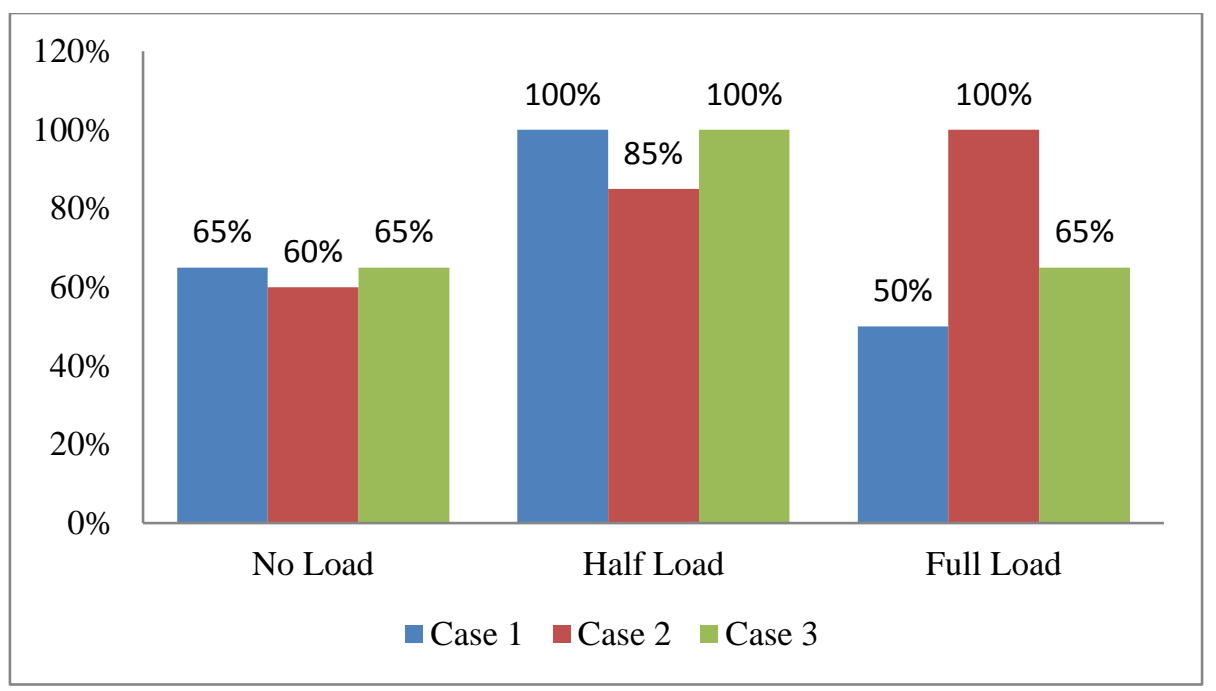

Fig. 16 - Comparison of percentage detection in all load variations

\section{Conclusion}

1. Analysis of the frequency spectrum on stator current can clearly detect the outer race bearing damage.

2. The success of detection analysis is based on changes in motor load rather than the severity

3. Half load conditions are most suitable for use in this system configuration, this is indicated by the highest percentage of success

4. Detection accuracy is unstable under full load conditions due to damping effect of mechanical loads

5. Unbalanced voltage affects the stator current so that the analysis of the frequency spectrum of the stator current is disrupted

6. Future work, bearing damage detection is carried on the inner race and ball bearing for comparison with the outer race bearing result, applying voltage stabilizers to facilitate the analysis process, applying different cases of bearing damage such as bearing contamination, broken bearings, etc.

\section{References}

[1] Chapman, Stephen J. (2005). Electric Machinery Fundamentals Fourth Edition. McGraw-Hill Companies, New York.

[2] Da Silva, Aderiano M. (2006). Induction Motor Fault Diagnostic And Monitoring Methods. Marquette University, Milwaukee, Wisconsin.

[3] IEEE Motor Reliability Working Group. (1998). Report of large motor reliability survey of industrial and commercial installations, Part I,. IEEE Trans. Ind. Appl., vol. IA-21, no. 4, pp. 853-864.

[4] O. V. Thorsen and M. Dalva. (1995). A survey of faults on induction motors in offshore oil industry, petrochemical industry, gas terminals, and oil refineries. IEEE Trans. Ind. Appl., vol. 31, no. 5, pp. 1186-1196, Sep./Oct. 1995.

[5] P. Tavner, L. Ran, J. Penman, and H. Sedding. (2008). Condition Monitoring of Rotating Electrical Machines, 2nd ed. Stevenage, U.K.: IET.

[6] Zhiqiang Liao, Peng Chen. (2018). A Vibration Signal Filtering Method Based on KL Divergence Genetic Algorithm - with Application to Low Speed Bearing Fault Diagnosis. 23rd International Conference on Digital Signal Processing (DSP), IEEE.

[7] Do-Jin Kim, Hae-Joong Kim, Jung-Pyo Hong. (2017). Estimation of Acoustic Noise and Vibration in anInduction Machine Considering Rotor Eccentricity. IEEE Transactions on Magnetics, Vol.50, No.2, pp 7021204.

[8] Gulamfaruk N. Surya, et al. (2017). Application of observer coil technique for detection of stator turn fault and damaged bearing in cage motors. National Power Electronics Conference (NPEC), IEEE.

[9] Navasari, Eva, et al. (2018). Detection Of Induction Motor Bearing Damage With Starting Current Analysis Using Wavelet Discrete Transform And Artificial Neural Network. 10th International Conference on Information Technology and Electrical Engineering (ICITEE)

[10] Quang Thinh Tran. et al. (2019). Algorithm for Estimating Online Bearing Fault Upon the Ability to Extract Meaningful Information From Big Data of Intelligent Structures. IEEE Transactions on Industrial Electronics.

[11] Alham. N. et al. (2018). Analysis of Load and Unbalance Voltage on Air gap Eccentricity in detection of Three Phase Induction Motor. International Conference on Information and Communications Technology (ICOIACT), IEEE.

[12] Jaehoon Kim, et al. (2012). Bearing fault effect on induction motor stator current modeling based on torque variations. 12th International Conference on Control, Automation and Systems.

[13] V. Fernão Pires, et al. (2015). Detection of stator winding fault in induction motors using a motor square current signature analysis (MSCSA). 5th International Conference on Power Engineering, Energy and Electrical Drives (POWERENG), IEEE. 
[14] Frosini Lucia and Bassi Ezio. (2010). Stator Current and Motor Efficiency as Indicators for Different Types of Bearing Faults in Induction Motors. IEEE Transactions on Industrial Electronics, Vol. 57, No. 1, Januari..

[15] Xiang Li, et Lal. (2013). Fault diagnosis based on nonlinear dynamic modeling in rolling element bearing system. International Symposium on Assembly and Manufacturing (ISAM), IEEE.

[16] Nandi Subhasis dan Toliyat Hamid A. (1999). Condition Monitoring and Fault Diagnosis of Electrical Machines A Review. Electric Machines \& Power Electronics Laboratory, Department of Electrical Engineering, Texas A\&M University.

[17] Vahid, Aref. (2019). An Efficient Nonlinear Fourier Transform Algorithm for Detection of Eigenvalues from Continuous Spectrum. Optical Fiber Communications Conference and Exhibition (OFC), IEEE.

[18] Ankush R. Kuralkar. (2015). Design of fast fourier transform using processing element for real valued signal. International Conference on Communications and Signal Processing (ICCSP), IEEE.

[19] Hayes, Monson H. (1999). Schaum's Outline of Theory and Problems of Digital Signal Processing. McGraw-Hill Companies, USA.

[20] Musa Tunç Arslan. (2014). Approximate computation of DFT without performing any multiplications: Application to radar signal processing. 22nd Signal Processing and Communications Applications Conference (SIU), IEEE. 